\title{
Challenges in simulating economic effects of climate change on global agricultural markets
}

\author{
Angelo C. Gurgel ${ }^{1}$ (1) - John Reilly ${ }^{1}$ (D) - Elodie Blanc ${ }^{1}$ (]) \\ Received: 29 May 2020 / Accepted: 10 May 2021 / Published online: 2 June 2021 \\ (C) The Author(s) 2021
}

\begin{abstract}
Many approaches have been used to investigate climate change impacts on agriculture. However, several caveats remain in this field: (i) analyses focus only on a few major crops, (ii) large differences in yield impacts are observed between projections from site-based crops models and Global Gridded Crop Models (GGCMs), (iii) climate change impacts on livestock are rarely quantified, and (iv) several causal relations among biophysical, environmental, and socioeconomic aspects are usually not taken into account. We investigate how assumptions about these four aspects affect agricultural markets, food supply, consumer well-being, and land use at global level by deploying a large-scale socioeconomic model of the global economy with detailed representation of the agricultural sector. We find global welfare impacts several times larger when climate impacts all crops and all livestock compared to a scenario with impacts limited to major crops. At the regional level, food budget can decrease by 10 to $25 \%$ in developing countries, challenging food security. The role of land area expansion as a major source of adaptation is highlighted. Climate impacts on crop yields from site-based process crop models generate more challenging socioeconomic outcomes than those from GGCMs. We conclude that the agricultural research community should expand efforts to estimate climate impacts on many more crops and livestock. Also, careful comparison of the GGCMs and traditional site-based process crop models is needed to understand their major implications for agricultural and food markets.
\end{abstract}

Keywords Climate change $\cdot$ Crop yield $\cdot$ Livestock productivity $\cdot$ Agricultural markets

\section{Introduction}

Studies dating to the 1980s have investigated climate change effects on agriculture, a sector highly exposed to the weather (Blanc and Reilly 2017). Porter et al. (2014) find that climate

Angelo C. Gurgel

gurgel@mit.edu

1 MIT Joint Program on the Science and Policy of Global Change, Cambridge, MA, USA 
change has already affected agriculture, and is a likely threat to future food security. Adaptation can reduce impacts or improve yields, but its effectiveness is highly variable (Porter et al. 2014).

Rosenzweig et al. (2014) identify three approaches used to investigate climate impacts on crops, including statistical analyses, biophysical process-based models, and agro-ecosystem models. In applying statistical analyses, a debate on whether panel data models (Blanc and Schlenker 2017), cross-section analyses (Mendelsohn and Massetti 2017), or agro-economic simulation models (Antle and Stöckle 2017) offer better insights. Mendelsohn and Massetti (2017) claim that the "Ricardian" approach represents a more complete estimate, by including adaptations such as shifting among crop and livestock or among different crops or types of livestock. The panel data approach has been applied to specific crops, capturing crop responses to weather, leaving it to further analysis to understand whether different practices might mitigate weather effects. Most results reviewed in Porter et al. (2014) were those based on site-level, crop models, often linked to economic simulation models, as discussed by Antle and Stöckle (2017). Rosenzweig et al. (2014) notes that site-based models consider the complexity of crop, soil, atmosphere, and management component interactions at the field level, while agro-ecosystem models deal with larger spatial scale simulations of the carbon and nitrogen dynamics, energy, soil, and water balance. Both approaches have been used to build Global Gridded Crop Models (GGCMs) that estimate crop yield impacts at the global scale.

This debate around methods has, however, left some glaring oversights in understanding the full risks related to climate impacts on agriculture. One omission arises from the focus on a few major crops, usually maize, wheat, rice, or soybeans (the Food and Agriculture Organization of the United Nations (FAO) lists over $170 \mathrm{crops}$ ). And while the literature documents extensively the adverse effects of heat on livestock productivity, there has been little attempt to quantify these effects at the national, regional, and global level. Global production of maize, wheat, rice, and soybeans was worth about 800 billion US dollars in 2016 but that amounted to only about $17 \%$ of the total value of all agricultural products (FAO 2019). While it is beyond this study to estimate separate yield effects for the $\sim 170$ other crops and various livestock, we test the sensitivity of including impacts on other crops and livestock by extending the impacts projected for the main crops to other agricultural commodities. Our first question is: If we extend climate productivity shocks beyond these few staples, how sensitive are food system projections?

A second issue is that site-based models require highly detailed local data. Once calibrated to a site's conditions and management practices, these models can replicate crop yields quite well. However, a relatively few sites are used to calibrate the regional model, raising questions about the representativeness for the entire region. GGCMs simulate potential yields in every grid (often at the $0.5^{\circ} \times 0.5^{\circ}$ latitude-longitude level), but assume static soil properties and/or management practices (Müller et al. 2017). Site-based models and GGCMs provide very different estimates of climate effects on crops (Müller et al. 2017). Our second question is: How do results from such different methods change our view of the climate threat to the food system?

A third issue is the potential impacts on the food system due to livestock productivity effects of climate. General effects are documented by Rojas-Downing et al. (2017). They range from effects on pasture and forage, to direct effects on animal productivity and health, to indirect effects on pathogens and disease vectors through changes in precipitation and temperature. Higher temperatures increase morbidity and death rates. Heat stress reduces body size, carcass weight, and fat thickness in ruminants. For poultry, productivity falls off especially at temperatures above $30{ }^{\circ} \mathrm{C}$. Studies indicate a current loss in the US of about 
$\$ 1.7$ to $\$ 2.4$ billion due to heat stress in the dairy and beef industry (Rojas-Downing et al. 2017). Overall, this review concludes that climate change will negatively affect the livestock sector. Summer et al. (2019) similarly shows declines in milk production of about 3 to $23 \%$ as the temperature humidity index rises beyond 72 and $80^{\circ} \mathrm{F}$, respectively, for high producing dairy cows, and slightly less (0 to 20\%) for low producing cows. The difficulty in arriving at quantification is that there are not straightforward relationships that can be applied at the regional or global level, or how effects vary by breed, management approach, and the effectiveness and cost of adaptive measures such as mist cooling, shade, and fans. Therefore, broad economic assessments of climate impacts on agriculture have generally neglected the impacts on livestock productivity and pastures. Our third question is: How sensitive are estimates of food system response to climate change when livestock productivity effects are considered?

To go beyond impacts on crop yields and livestock productivity, there are various causal relationships and feedbacks among biophysical, environmental, and socioeconomic systems to be considered, bringing additional uncertainties to these projections of impacts on the food system (Gornall et al. 2010). We attempt to consider many of the complex socioeconomic relationships and feedbacks by using estimates of agricultural productivity changes within a large-scale model of the global economy with newly added details on the agriculture sector. The model allows for changes in management (substitution of other inputs as land productivity changes) as an adaptation response. It also simulates changing demand for food as prices and incomes change, along with changing patterns of global trade. Other studies have used similar models (e.g. Nelson et al. 2014), although few consider changes in crop and pasture areas as a response to productivity shocks from both crops and livestock. Our fourth question is: Combining impacts on all crops and livestock, how sensitive is the food system to climate?

Our focus on these four questions (or glaring omissions) is to identify the potential importance of these overlooked and still debated effects, calling the attention of the agriculture-climate research community in an effort to prioritize these research gaps.

\section{Material and methods}

We adapt an existing socioeconomic model of the global economy with an explicit characterization of multiple markets for primary factors (land, fossil fuel resources, labor, capital), energy, agriculture, food, industrial goods and services, and all relationships among such markets, including international trade. We then apply shocks on crop yields and livestock productivity into the economic model. Such shocks are based on the compilation of climate impacts on crops by the IPCC (Porter et al. 2014) and on our own simulation of crop yields using Blanc (2017a) GGCMs crop emulators.

\subsection{The EPPA-agriculture model}

The MIT Emissions Prediction and Policy Analysis (EPPA) model, version 6, is a recursivedynamic multi-regional and multi-sectorial computable general equilibrium (CGE) model of the world economy (Chen et al. 2015). The underlying economic data is sourced from the Global Trade Analysis Project Version 8 (GTAP 8) database, for the year 2007 (Narayanan et al. 2012). It provides the base information on social accounting matrices and the structure for regional economies, including bilateral trade and energy markets in physical units (Hertel 
1997; Narayanan et al. 2012). In the original version of EPPA6, the data is organized into 18 regions and 14 sectors. We expand the sectoral representation to 28 sectors, improving the definition of agricultural and livestock sectors and commodities (Table 1). ${ }^{1}$ The conventional version of EPPA contains three aggregated land sectors: crops, livestock, and forests, while EPPA-Agriculture breaks them in eight crop sectors and three livestock sectors.

Table 1 also presents the primary factors inputs represented in EPPA-Agriculture. Among them are both depletable and renewable natural capital inputs, as well as produced capital and labor. EPPA treats cropland, pastures, and managed forest land as "produced" from natural capital of forest areas and grasslands. We also parameterize several energy production "backstop technologies" not identified in the base year data, either because they were not deployed or only at relatively low levels but could be deployed in the future under price or policy conditions (see Table S2 in the Supplementary Material). Backstop technologies are represented in a similar fashion as in earlier EPPA versions (see Chen et al. 2015).

Household transportation including purchased commercial and own-supplied transport is also represented in EPPA, requiring additional data to disaggregate vehicle use within the GTAP data. Chen et al. $(2015,2017)$ describe the disaggregation and parameterization of transport and electric power generation, which uses bottom-up engineering costs, fuel use, and conversion efficiency.

EPPA incorporates data on greenhouse gases (GHG) (CO2, CH4, N2O, HFCs, PFCs, and SF6) and air pollutant emissions (SO2, NOx, black carbon, organic carbon, NH3, CO, VOC), based on data from the International Energy Agency (IEA 2012) on CO2 emissions from energy consumption, Boden et al. (2010) for emissions from cement production, the Emissions Database for Global Atmospheric Research (EDGAR) Version 4.2 (European Commission 2011), and Bond et al. (2007) for non-CO2 GHGs and conventional air pollutants.

The model simulates historical economic trajectories recursively for 2010 and 2015, and then projects future economic pathways at 5-year intervals from 2015 to 2100 . Economic development through 2020 is benchmarked to historical data and short-term GDP projections of the IMF. The model is formulated as a mixed complementary problem (MCP) (Rutherford 1995) and solved using the MPSGE subsystem in GAMS programming language (Rutherford 1999).

Future projections are driven by economic growth resulting from savings and investment, and exogenously specified productivity improvement in labor, capital, land, and energy. GDP and income growth through time increase demand for goods and services, including food. Higher cost grades of depletable resources are accessed as lower cost stocks are depleted. Sectors using renewable resources compete for the available flow of services from them, generating rents. Backstop and advanced technologies may become cost competitive as regular energy sources become more expensive. These various economic drivers, combined with imposed policies and shocks, determine the economic trajectories over time and across scenarios.

Explicit modeling of land use that maintains consistent supplemental physical accounts is a unique feature in EPPA. The approach considers five broad land use categories: cropland, pasture, forest, natural forest, and natural grass. We reconcile several world scale data sources to build the land use change approach. We use the "GTAP8 Land Use and Land Cover Database" (Baldos and Hertel 2012). It is built from FAOSTAT production data as well as cropland and pasture data from Ramankutty (2012). We complement these with data from the

${ }^{1}$ Figure S1 in the Supplementary Material displays the EPPA regions and Table S1 describes the agricultural sectors. 
Table 1 Regions, sectors, and primary factor inputs in EPPA-Agriculture

\begin{tabular}{|c|c|c|c|c|c|}
\hline \multicolumn{2}{|l|}{ Regions } & \multicolumn{2}{|l|}{ Sectors } & \multicolumn{2}{|c|}{ Primary factor inputs } \\
\hline $\begin{array}{l}\text { United States } \\
\text { (USA) }\end{array}$ & Africa (AFR) & Rice & Coal & $\begin{array}{c}\text { Depletable } \\
\text { natural }\end{array}$ & $\begin{array}{l}\text { Conventional oil } \\
\text { resources }\end{array}$ \\
\hline $\begin{array}{l}\text { Canada } \\
\text { (CAN) }\end{array}$ & $\begin{array}{l}\text { Middle East } \\
\text { (MES) }\end{array}$ & Maize & Crude oil & capital & Shale oil \\
\hline $\begin{array}{l}\text { Mexico } \\
\qquad(\mathrm{MEX})\end{array}$ & $\begin{array}{l}\text { Latin } \\
\text { America } \\
\text { (LAM) }\end{array}$ & Soybean & Refined oil & & $\begin{array}{l}\text { Conventional gas } \\
\text { resources }\end{array}$ \\
\hline $\begin{array}{l}\text { JAPAN } \\
(\text { JPN })\end{array}$ & & Wheat & Gas & & $\begin{array}{l}\text { Unconventional gas } \\
\text { resources }\end{array}$ \\
\hline $\begin{array}{l}\text { Australia and } \\
\text { New Zealand } \\
\text { (ANZ) }\end{array}$ & & Sugar crops & Electricity & & Coal resources \\
\hline $\begin{array}{l}\text { Europe } \\
\text { (EUR) }\end{array}$ & & $\begin{array}{l}\text { Vegetables } \\
\text { and fruits }\end{array}$ & $\begin{array}{l}\text { Non-metallic } \\
\text { minerals }\end{array}$ & $\begin{array}{c}\text { Renewable } \\
\text { natural }\end{array}$ & Natural forest \\
\hline $\begin{array}{l}\text { Eastern } \\
\text { Europe } \\
\text { (ROE) }\end{array}$ & & Fiber plants & Iron and steel & capital & Natural grasslands \\
\hline Russia (RUS) & & Other crops & Non-ferrous metals & & Solar and wind resources \\
\hline $\begin{array}{l}\text { East Asia } \\
\qquad(\mathrm{ASI})\end{array}$ & & $\begin{array}{l}\text { Bovine } \\
\text { cattle }\end{array}$ & $\begin{array}{l}\text { Other } \\
\text { energy-intensive } \\
\text { Industries }\end{array}$ & & Hydro resources \\
\hline $\begin{array}{l}\text { South Korea } \\
\text { (KOR) }\end{array}$ & & $\begin{array}{l}\text { Poultry and } \\
\text { pork }\end{array}$ & Other industries & $\begin{array}{r}\text { Produced } \\
\text { capital }\end{array}$ & $\begin{array}{l}\text { Conventional Capital } \\
\text { (Bldgs. and Mach.) }\end{array}$ \\
\hline $\begin{array}{l}\text { Indonesia } \\
\text { (IDZ) }\end{array}$ & & $\begin{array}{l}\text { Other } \\
\text { livestock }\end{array}$ & Construction & & Cropland \\
\hline China $(\mathrm{CHN})$ & & Forestry & Other services & & Pasture and grazing land \\
\hline India (IND) & & $\begin{array}{l}\text { Wood } \\
\text { products }\end{array}$ & Transport & & Managed forest land* \\
\hline Brazil (BRA) & & $\begin{array}{l}\text { Food } \\
\text { products }\end{array}$ & $\begin{array}{l}\text { Ownership of } \\
\text { dwellings }\end{array}$ & & Labor \\
\hline
\end{tabular}

*Includes managed forest areas for forestry production and secondary forests previously used for wood extraction and agricultural purposes (natural vegetation re-growth)

Terrestrial Ecosystem Model (Felzer et al. 2004), using historical land use transitions from Hurtt et al. (2006). ${ }^{2}$

We represent land use and conversion in physical terms. The model explicitly considers conversion costs, so that land improvements (draining, tilling, fertilization, fencing) can convert pastureland to cropland, or forestland can be harvested, cleared, and used as pastureland or cropland. If investment in cropland is not maintained, the land can go back to a less intensely managed use (pasture, or forest) or be abandoned and return to "natural" grass or forest land. The conversion of natural forests produces timber, similarly to a forest harvest on managed forest land. Transformation of natural areas to agricultural use is calibrated to mimic a land supply response based on land conversions observed over the past few decades. A "nonuse value" is calculated for representing initial rents of natural forests. It combines the cost of access to remote timber land and data from an optimal timber harvest model for each region and timber type. The land use transformation approach avoids the limitations of the commonly used Constant Elasticity of Transformation (CET) function and is well suited to longer-term analysis where demand for some land uses could expand substantially (Schmitz et al. 2014).

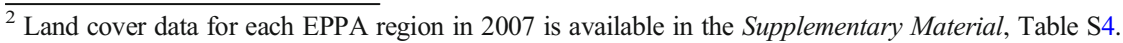


We consider exogenous average yield improvements of $1 \%$ per year, consistent with Ray et al. (2013). Agricultural land, capital, labor, energy, and intermediate inputs are combined under multi-nested Constant Elasticity of Substitution (CES) functions to produce agricultural goods. These become inputs to other sectors, mainly to the food industry. Households demand allows for substitution among goods, including food and agricultural products, which have income elasticities lower than one. More details can be found in Gurgel et al. (2016) and in the Supplementary Material (Section 2).

All these features of the model capture the major climate change adaptation mechanisms in agriculture: changes in the extensive margin (land conversion), changes in the intensive margin (land intensification through substitution of other inputs for land), demand responses due to price changes, shifts among crops, and between crops and livestock, and redistribution of crops among regional and global cropland area through international trade.

\subsection{Scenarios}

Our goal is to give an indicative quantitative answer to the caveats and questions identified in the "Introduction" section. Our strategy is to compare results through 2050 from the EPPAAgriculture model for which climate change impacts on the agriculture sector are represented using estimates from traditional regional-scale studies using site-based models as summarized by the IPCC, to global-scale results from GGCMs. We then compare those results to simulations assuming average impacts on crops not covered in these studies. Finally, we extend these impacts to pasture and livestock productivity. While it seems unlikely that other crops and livestock will be affected in the same way as the four major crops often studied, we intend for this to be a sensitivity analysis helping to establish the priority the research community might place on estimating climate impacts on a more comprehensive set of agricultural commodities. We also compare the climate effects scenarios against a baseline $(B A U)$ assuming no climate change. We can then use several metrics to quantify the overall socioeconomic, agriculture sector, and environmental effects associated with adapting to climate change.

\subsubsection{Comparing conventional crop model results to GGCMs'}

Based on results reported in Porter et al. (2014), we calculate a median crop response to climate change by 2050 for each EPPA region for four main crops. The median estimates for each crop span both a variety of crop models and different climate scenarios. ${ }^{3}$

Blanc (2017a) developed statistical emulators of the major GGCMs. Two models, pDSSAT and GEPIC, are site-based models applied at the global level, while the three others, LPJGUESS, LPJmL, and PEGASUS, are global ecosystem models integrating site-based model mechanisms and parameters (Müller et al. 2017). They estimate crop yields at a fine resolution $\left(0.5^{\circ} \times 0.5^{\circ}\right.$ degree $)$ globally by considering the detailed effect of weather (monthly, daily, or even hourly) on crop growth (Bassu et al. 2014). Similar to the IPPC results, these models are largely limited to four major crops: rice, maize, soybean, and wheat (RMSW). The emulators were used to simulate yields under nine climate scenarios, providing a total of 45 separate simulations for each crop and grid cell. Inputs from the nine scenarios were obtained from the Massachusetts Institute of Technology Integrated Global System Modeling (MIT IGSM) framework using a pattern scaling method (Schlosser et al. 2013) under GHG emissions

\footnotetext{
$\overline{{ }^{3} \text { We provide more details in the Supplementary Material, Section } 3 .}$
} 
scenarios consistent with the Paris climate agreement (COP21). The pattern-scaling method uses global-scale simulations of the MIT IGSM to estimate the effect of uncertainty in climate sensitivity, ocean heat uptake, and aerosol forcing on latitudinal climate change combined with longitudinal patterns from major general circulation models simulations available through Climate Model Intercomparison Projects (CMIPs). The nine climate scenarios include a high, median, and low climate response to GHG forcing, and three different climate model patterns. We estimate the mean of 45 crop responses simulations for each region for the 2050 period, using a 5-year average yield response for between 2047 and 2052.

The central tendency from the IPCC site-based models is for negative effects on yields for nearly all crops and regions, while the central tendencies for the emulated GGCMs results are mostly positive (Fig. 1). ${ }^{4}$ We have plotted all results for both the IPCC and emulated GGCMs using the same $y$-axis scale to better show differences. The yield range differs among IPCC estimates and the emulated GGCMs. The GGCM range is especially wide for rice, and more in line with the IPCC range for maize and wheat, with the exception for a few regions. Each approach has strengths and weaknesses. The site-based models typically are calibrated to represent current yields quite well at the sites where they are applied and are simulated at highly resolved time steps. They may better capture the response to extremes. However, if spatial variation smooths out the response of crops over a wide region, the limited number of sites typically simulated may not capture this smoothing, or the sites may not be broadly representative of the large regions they are used to represent. The GGCMs are simulated in every land grid cell. For our comparisons, we have used results only for grids in which the crops are currently grown. These may then be more representative of a large region and may smooth out local variability. However, given the range of crop cultivars and management practices and limited data, the GGCM results are generally not calibrated closely to current yields, and with generally coarser time steps may not capture well weather extremes.

\subsubsection{Extending impacts to all crops}

RMSW are important crops, but account for only $17 \%$ of value of the global agriculture production. We extend impacts to other crops by applying the simple average impact of the four main crops in each region to all other crops represented in EPPA. Although it is a simplistic assumption, it avoids an outcome where production is simply shifted to crops that were left unaffected only because no yield estimates were available. By assuming all crop production is being affected by climate, we investigate how results may be biased by only simulating impacts on some crops. We identify such scenarios as "Crops".

\subsubsection{Extending impacts to livestock}

Livestock productivity will be directly affected by changes in climate but also indirectly by changes in the price and availability of livestock feed. However, the literature is very scarce on the potential impacts on livestock production and pastures. Given the lack of information, we consider one more subset of scenarios, labeled "Crops \& Livestock", with climate impacts extending to all crops, pasture yields, and livestock productivity.

\footnotetext{
${ }^{4}$ The comparison between IPCC and GGCM projections from Rosenzweig et al. (2014) differs from these results due to differences in methodology (mean vs. median impacts, different regional delineations, and categorization of GGCMs with and without explicit nitrogen stress).
} 

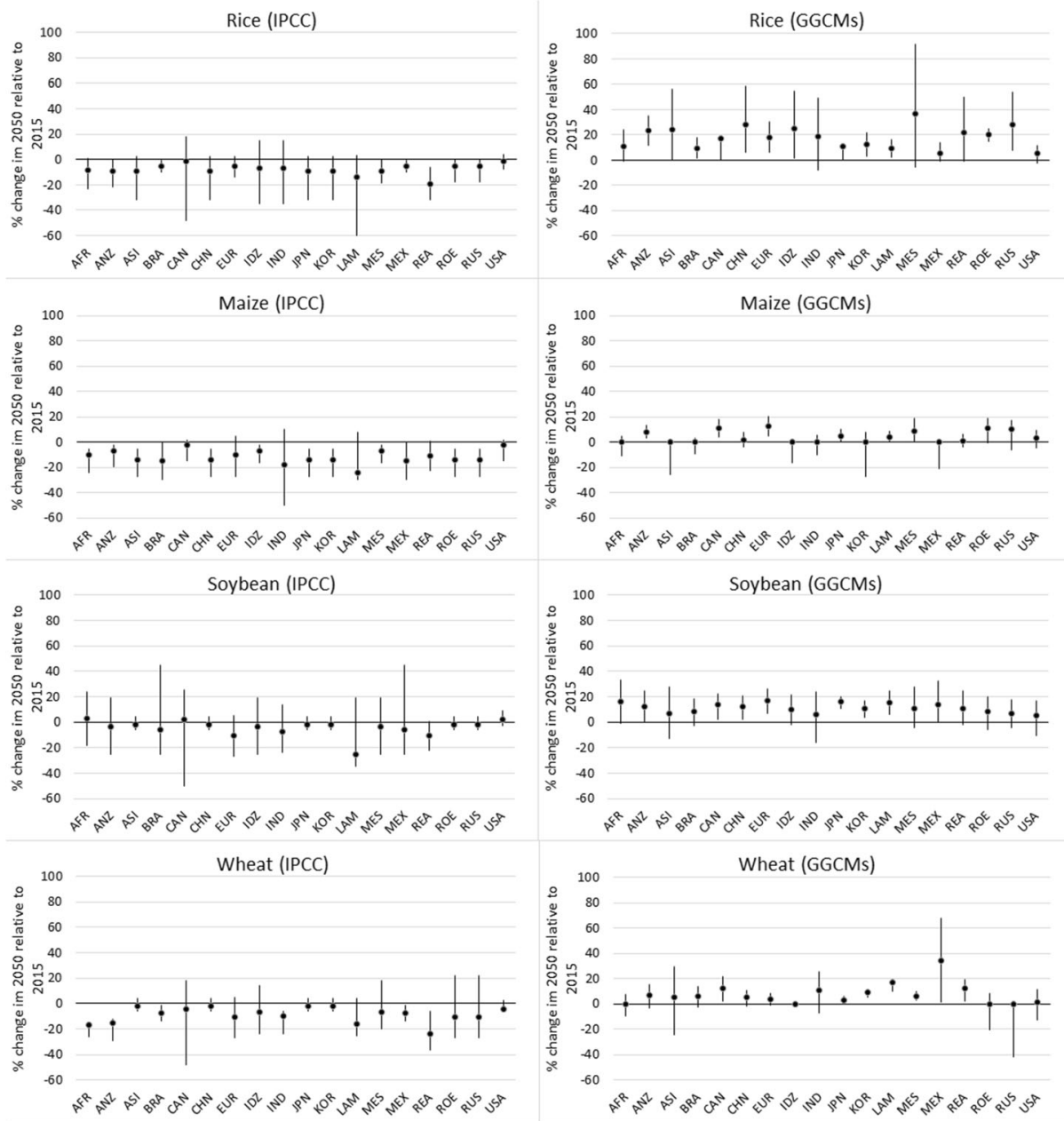

Fig. 1 Range of climate impacts on yields by 2050 from IPCC and GGCMs. Source: Author's compilation based on Porter et al. (2014) and author's estimation using five crop emulators based on Blanc (2017a, 2017b)

In summary, we simulate three subsets of scenarios: (i) climate impacts only on $R M S W$ yields, (ii) climate impacts on yields of all crops (Crops), and (iii) climate impacts on all crops and pasture yields and livestock productivity (Crops \& Livestock). Both of these last two scenarios extend either the IPPC RMSW or GGCM RMSW impacts to the other commodities. The exception is that if the average crop yield impact is positive, we do not assume direct effect on livestock productivity, only on pasture yields. Table S7 in the Supplementary Material lists all scenarios.

While Fig. 1 shows ranges of impacts on crop yields, we focus our analysis on the median estimates both for the IPCC RMSW and GGCM RMSW responses. There is considerable variability in the median impacts among crops and among regions for each crop. The range of impact for both the IPCC and GGCM sets of impacts are quite wide, with the range often including both increases and decreases in yields. The median $G G C M$ results are positive for crops in all regions. In contrast, the median IPCC impact is negative for nearly all crops and all regions, with the exception being small increases in soybean yields in a couple of regions. 
We linearly interpolate yield changes from zero in 2020 to the 2050 median yield impacts for both IPCC and emulated GGCM scenarios when implemented in EPPA-Agriculture. Yield impacts on crops are applied in the model as a shock to land use productivity, and productivity impacts on livestock activities are applied as shocks to their total factor productivity.

\section{Results}

Given the complex interactions among regions through trade, and within the agricultural sector in terms of food consumption, crops, livestock, land use change, and land use emissions, we identify several metrics to quantify the potential economic importance of some of the major oversights we have seen in evaluating agricultural risks from climate change. These included metrics that cover (i) broader socioeconomic impacts, (ii) agriculture sector impacts, and (ii) environmental implications of climate change, acting through impacts on agriculture.

\subsection{Socioeconomic metrics}

The change in macroeconomic welfare measured as equivalent variation - the change in the total value of all goods consumed by households - is the broadest economic indicator (or synthesis) of all effects and adjustments in the human activities needed to accommodate the impacts of climate changes on crop yields. As demand for food is relatively price inelastic, for a given yield decline, demand will adjust downward by less than the yield loss. To meet the still relatively high demand, resources will be diverted from other parts of the economy to increase food supplies. Our measure of welfare includes reductions in consumption of other goods because of the diversion of resources toward agriculture. Another useful socioeconomic metric is the effect on the household budget share for food. Here, we compare the aggregate welfare changes at the global and regional level, and how the food budget share changes for the representative agent in each region.

Global aggregate welfare impacts are six to 13 times larger in the Crops \& Livestock scenarios compared with the RMSW scenarios and two to three times larger in the Crops scenarios compared with the $R M S W$ scenarios (Table 2). The $R M S W$ scenarios, by covering only a fraction of all products, will underestimate the total welfare impact on the economy. However, the effect is magnified by the fact that having some commodities unaffected by climate change allows a further avenue of adaptation - simply shifting away from negatively affected crops toward commodities left unaffected. By construction, the yield shocks in the Crops \& Livestock scenarios are similar across all commodities, so there is essentially no shift toward unaffected commodities, completely shutting off that mode of adaptation. Obviously, this may be extreme as the climate responses are likely to vary among different agricultural commodities. However, it often appears to be the case that a family of crop models applied to different crops gives somewhat similar yield changes. The comparison between the regionalscale "family" of site-based models in the IPCC scenarios and the global-scale "family" in the $G G C M$ scenarios illustrate this tendency. Hence, if we are able to construct a full set of impacts for all commodities using a standard approach, it seems more likely that there would be less variation in impact among commodities than we might get by randomly selecting from a large range. If, for example, half of the estimates came from GGCM-based estimates, and half came from IPCC-reviewed site-based model estimate, they might well completely cancel each other out. But that seems a misapplication of fundamental differences in models to a scenario of how climate change might actually affect agriculture. 
Table 2 Global and Regional changes in welfare in 2050 relative to $B A U$

\begin{tabular}{lllllll}
\hline & IPCC-RMSW & IPCC-crops & $\begin{array}{l}\text { IPCC-crops } \\
\text { and livestock }\end{array}$ & GGCM-RMSW & GGCM-crops & $\begin{array}{l}\text { GGCM-crops } \\
\text { and livestock }\end{array}$ \\
\hline AFR & -0.1 & -0.1 & -2.1 & 0.1 & 0.0 & 0.5 \\
ANZ & 0.0 & 0.1 & 0.3 & -0.1 & -0.1 & -0.2 \\
ASI & -0.1 & -0.2 & -0.9 & 0.2 & 0.2 & 0.4 \\
BRA & 0.0 & 0.0 & 0.1 & -0.2 & -0.2 & -0.3 \\
CAN & 0.1 & 0.1 & 0.6 & -0.1 & -0.1 & -0.2 \\
CHN & -0.3 & -0.6 & -4.7 & 0.4 & 0.8 & 3.4 \\
EUR & 0.0 & 0.0 & 0.0 & 0.0 & 0.0 & -0.1 \\
IDZ & -0.6 & -0.9 & -3.5 & 1.2 & 1.4 & 2.6 \\
IND & -0.1 & -2.3 & -4.3 & 0.3 & 1.2 & 1.9 \\
JPN & 0.0 & 0.0 & 0.2 & 0.0 & 0.0 & -0.1 \\
KOR & -0.1 & 0.0 & -0.2 & 0.0 & 0.0 & 0.1 \\
LAM & -0.4 & -0.6 & -2.4 & 0.0 & 0.1 & 0.1 \\
MES & -0.2 & -0.4 & -1.5 & 0.1 & 0.4 & 0.9 \\
MEX & 0.0 & -0.1 & -0.3 & 0.0 & 0.0 & 0.1 \\
REA & -0.7 & -1.6 & -14.7 & 0.4 & 0.9 & 4.9 \\
ROE & 0.0 & 0.1 & -0.4 & 0.0 & -0.1 & 0.0 \\
RUS & 0.0 & -0.1 & -0.7 & 0.0 & 0.1 & 0.3 \\
USA & 0.0 & 0.0 & 0.2 & 0.0 & 0.0 & -0.1 \\
World & -0.1 & -0.3 & -1.3 & 0.1 & 0.2 & 0.6 \\
\hline
\end{tabular}

Welfare deviations in 2050 relative to $B A U$ for each EPPA region are often much stronger than global welfare changes (Table 2 presents losses in red and gains in blue). The IPCC scenarios show many more regions with negative impacts, and a very large $(-14.7 \%)$ impact for Rest of East Asia (REA) in the Crops \& Livestock scenario, and quite large impacts (3.5 to nearly 5\%) in India, China, and Indonesia, some of the most populated places in world, with relatively little option to expand cropland. The REA region has the most negative direct impacts on yields, consistent with the fact that it has the strongest aggregate economic effect. But many other factors combine to result in a large net impact on a region. For example, in the $G G C M$ scenarios, we see both losses and gains among regions even though the direct effects on yield are positive in all regions. This reflects changing terms of trade among regions. Notably, major agricultural exporters including ANZ, CAN, BRA, and to a lesser extent EUR and USA are among the negatively affected regions while importing regions are more likely to gain. These terms of trade effects also are operating in the IPCC scenarios, generating gains for many agricultural exporting regions and aggravating losses in importing regions.

Our second socioeconomic metric is the change from $B A U$ in the food budget share for the representative household in each region (Fig. 2). For the RMSW and Crops scenarios, the changes are relatively small, generally less than a couple of percent. The direction of budget share change is the same across all regions, although higher under the IPCC scenarios than under the $G G C M$ scenarios. This reflects the fact that yield changes are negative almost everywhere in the IPCC scenarios and positive in the GGCM scenarios, and food price changes are further tied together because of food and agriculture trade.

While the RMSW and Crops scenarios result in small budget share effects, the effects under the Crops \& Livestock scenarios are quite large, especially for the negative shocks in the IPCC Crops \& Livestock. There are a few reasons for the "undampened" effect on household food budgets. First, with all food items rising in price, there is less ability to substitute than in cases where the price of some items did not rise because there was no direct climate effect on them. 


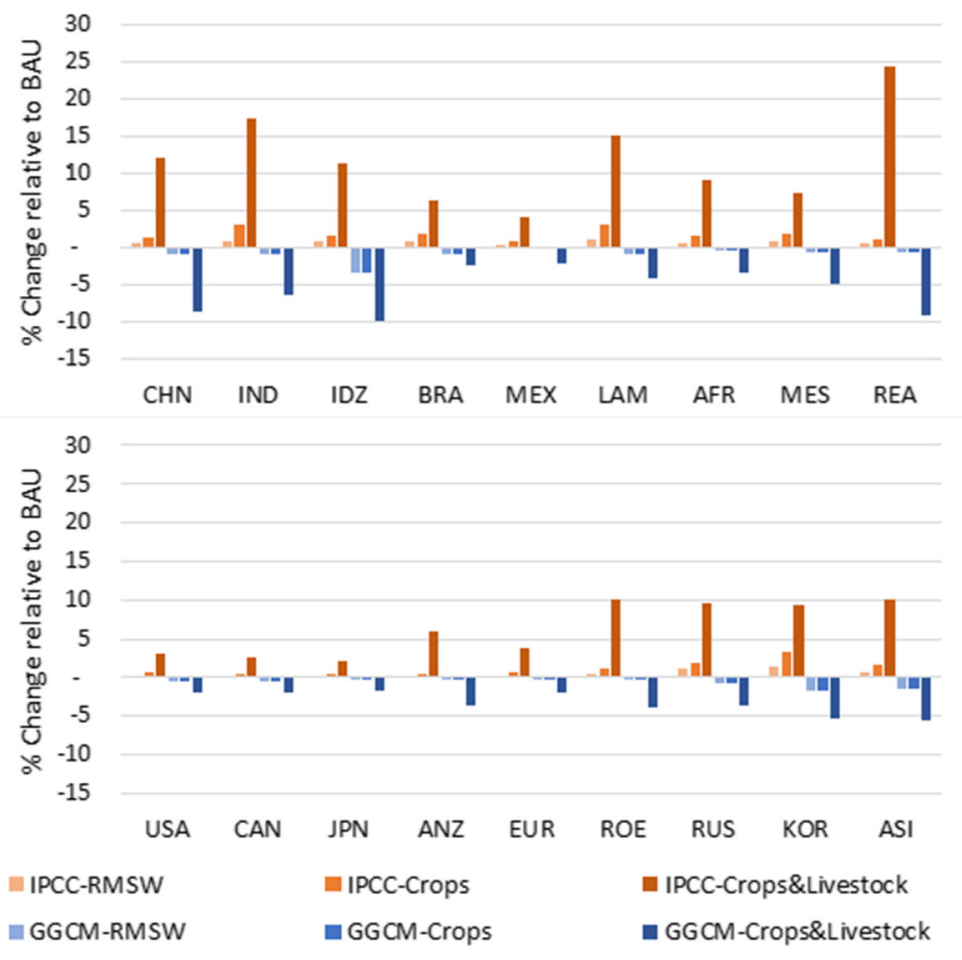

Fig. 2 Change in food budget share in 2050 relative to BAU

Second, while there can be substantial substitution among food items, overall food is relatively price inelastic, and so the result is that relatively more income is spent on food, reducing spending on non-food items. Third, the commodity cost of livestock products in final goods is much higher than the commodity cost of crops, where there is generally more value added. If $90 \%$ of the final food cost is value-added, then the consumer sees only $10 \%$ of the commodity price shock. Whereas, in livestock, where the commodity cost represents $70 \%$ of the final food cost, the consumer sees most of the commodity cost shock.

Value-added differences in food consumption between richer and poorer countries also explain why we see bigger impacts in poorer countries. In the USA, CAN, EUR, and JPN, the impact on the household budget share is well under 5\%. This reflects the purchase of more prepared foods, with higher valued added, and a large portion of the food budget spent eating out, where the commodity cost of food is dwarfed by labor and other valued added costs.

Similar to countries characterized by different income levels, if we were able to model households of different income levels within a region, we would likely see some of these effects amplified for the poorest households, and we would see households within the wealthier countries affected even more. Poor households would benefit under GGCM scenarios. However, the effects in the IPCC Crops \& Livestock scenario are worrisome. A bigger share of low-income households' budget is spent on food, and so it would mean, in percentage terms, cutting back much more on other goods than in wealthier households. And, finally, these scenarios are constructed to represent an average yield effect across several years that are representative of the 2050s. Any 1 year could be much worse (or much better). While wealthy 
households have more flexibility, by borrowing or temporarily tapping into savings to balance out such swings, poorer households are generally more constrained.

\subsection{Agriculture sector metrics}

Our agriculture sector metrics include changes in commodity production and prices and international trade. The initial yield and productivity shocks we have used to represent climate change effects are generally moderated by adaptation responses to the initial yield shocks. For a negative yield shock, adaptation may include substitution of other inputs to make up for the yield loss, expansion of land devoted to the crop, strategic storage, and reduction in use - and conversely for a positive yield shock. There may also be shifts in supply among regions to those less negatively or more positively affected, and among crops and livestock, again to those commodities less negatively or more positively affected.

Crop and livestock outputs are higher under positive climate impacts in the GGCM scenario than in the BAU scenario, and lower under the IPCC scenarios by 2050 (Fig. 3). ${ }^{5}$ When climate impacts are imposed only on $R M S W$ crops, agriculture outputs deviate less than $1 \%$ from the BAU projections in 2050. When all crops suffer yield impacts (Crop Only scenarios), outputs deviate at most by $1.5 \%$ from BAU. When all crops and livestock are affected, some crop and livestock outputs decrease more than $5 \%$. Food output falls just over $2 \%$ under the worst-case scenario.

The supply changes are generally much smaller in percentage terms than the initial yield shocks. For comparison, yield shocks in the IPCC scenarios are mostly in the range of -5 to $-14 \%$ for rice, -7 to $-24 \%$ for maize, -2 to $-11 \%$ for soybean, and -7 to $-17 \%$ for wheat, with a few outliers among regions. In the IPCC RMSW scenario, the impact on output is in the order of one-tenth the yield shock. And about one seventh the yield impact in the IPPC Crops scenario. But in the IPCC Crops \& Livestock scenario, it is on order one half the yield shock. We also see lower output in the non-impacted commodities in the IPCC RMSW and IPCC Crops \& Livestock scenarios. Two main channels of adaptation are the expansion of area devoted to the impacted commodities and international trade. When all commodities are directly negatively affected by climate change, then they are all competing to expand area to make up for lost yield, so there is less scope for economic adaptation than when few crops are directly affected (see Section 3.3). Trade in agricultural commodities also increase by 10 to $40 \%$ under broad negative climate impacts (Fig. 4). The situation is reversed in the GGCM scenarios where increasing yields reduce pressure on crop and pasture areas and on international trade. The sharp change in global trade under Crop \& Livestock scenarios is evidence of the relevance of global markets to mitigate climate change impacts on the food system.

Global price indices for crop, livestock, and food sectors vary from the $B A U$ as supply and demand adjust under climate impacts on yields over the period 2015 to 2050 (Fig. 5). ${ }^{6}$ For most crops, prices are reduced from $B A U$ prices under the GGCM scenarios and increased under the more negative IPCC scenarios. Under the $B A U$ scenario, crop prices are generally fairly stable over the projection period, with the

\footnotetext{
${ }^{5}$ Impacts on agricultural output for main regions are available in the Supplementary Material, Figure S6.

${ }^{6}$ Walsh Price Index (see Section 4 in the Supplementary Material).
} 


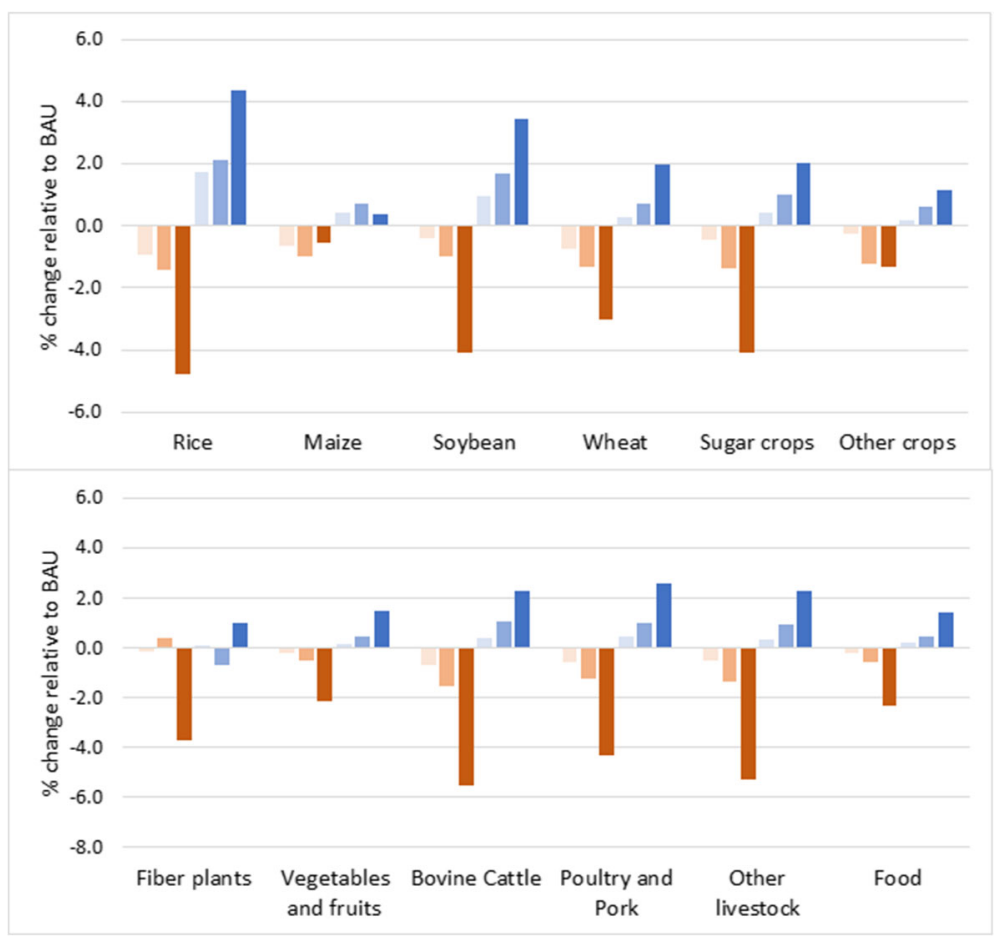

Fig. 3 Global change in output index in 2050 relative to BAU

exception being Other Crops, where prices increase by about $30 \%$. Under the IPCC scenarios, crop prices tend to increase above the $B A U$, rising in the range of 10 to $30 \%$ by 2050 from their 2015 levels. The Other Crop price index rises higher (by as much as $50 \%$ ) above 2015 levels, reflecting the greater increase in the $B A U$. Under the $G G C M$ scenarios, prices are 10 to $15 \%$ less than under the $B A U$ scenario for most crop sectors by the middle of the century. But in the case of other crops, prices may increase by $50 \%$ compared to 2015 price levels under the IPCC Crops \& Livestock scenario.

Under the $B A U$ scenario, EPPA-Agriculture projects for livestock sector prices to rise substantially. The differential effect reflects a higher income elasticity for meat, and with incomes rising across the world this implies more rapidly growing demand for livestock products. We do not see much impact on the $B A U$ livestock product prices under the RMSW and Crops scenarios. However, we see substantial additional increases in the IPCC Crops \& Livestock scenario (as much as a $270 \%$ increase above 2015 prices). When all crops and livestock yields are impacted by climate change, changes in prices are higher for both crops and livestock sectors than in scenarios where shocks are applied to major crops or all crops. These results reinforce the importance of land use changes as a mitigation strategy in agriculture and livestock. In the GGCM Crop and Livestock scenario, we see some decline, from $B A U$, in both crop and livestock sector prices. 


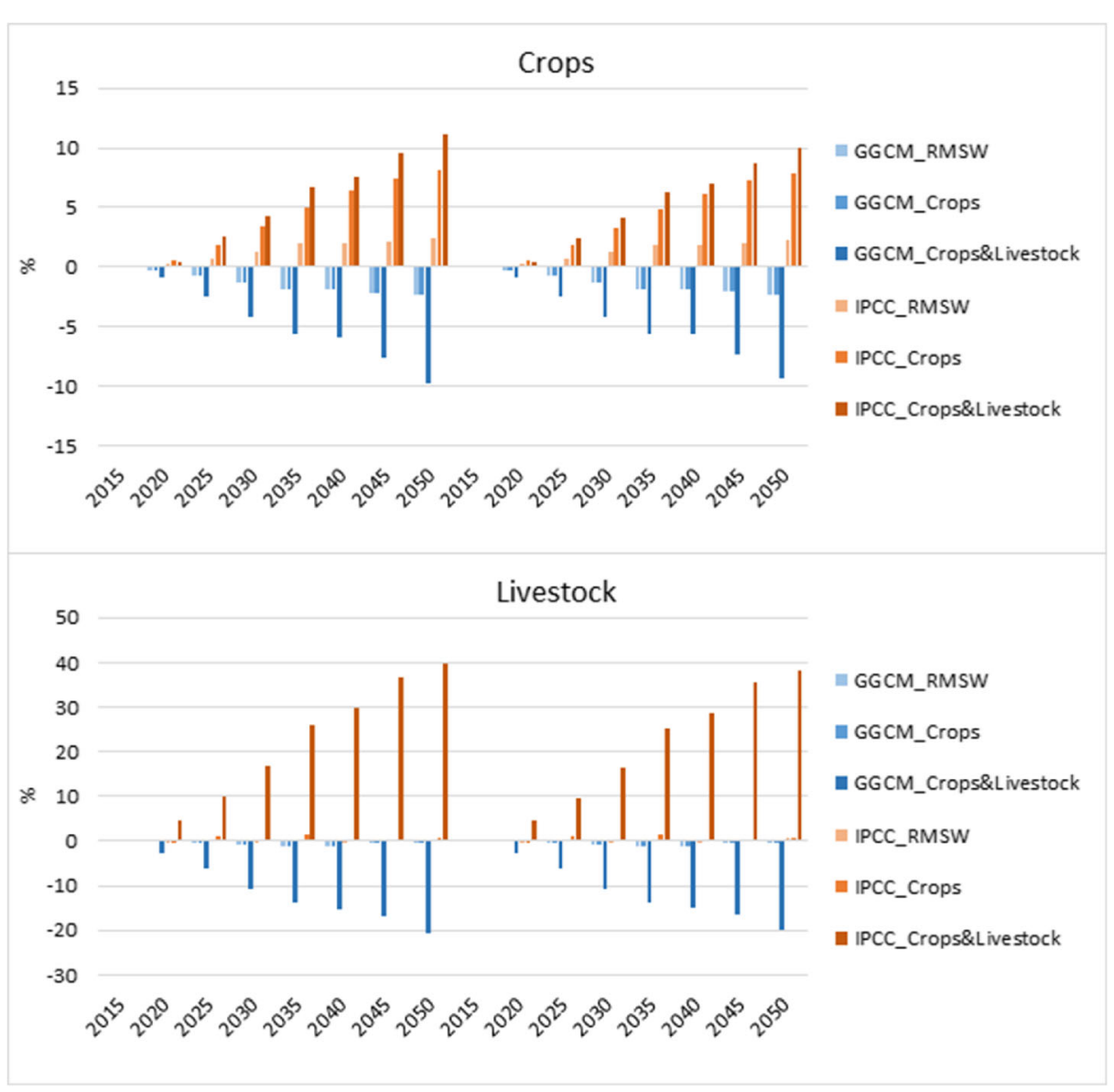

Fig. 4 Changes in the aggregate value of global exports and imports of crops and livestock relative to BAU

\subsection{Environmental metrics}

To evaluate environmental impacts, we look at changes in land use and in $\mathrm{CO}_{2}$ emissions from land. Bringing more land under cultivation or for use as pasture, in response to broadly negative impacts on crop and livestock, can be an important adaptation response to make up for lost yields. However, further encroachment of agriculture into natural lands may threaten biodiversity, and the deforestation and disruption of natural lands generally leads to release of carbon from the soils and vegetation as it decays or is burned.

For all IPCC and GGCM scenarios, the main land use changes from $B A U^{7}$ are among managed land use types (Fig. 6). For the IPCC RMSW and IPCC Crops scenarios, cropland increases by about 40 and 100 Mha more than in the $B A U$, respectively. A $5 \%$ increase in cropland area in 2050 relative to $B A U$ compensates for an aggregated shock of $9.1 \%$ loss in yields worldwide. ${ }^{8}$ Much of this increase in both the RMSW and Crops scenarios is at the

\footnotetext{
${ }^{7}$ Land use changes in the BAU scenario are presented in the Supplementary Material, Figures S7 and S8.

${ }^{8}$ For changes in the intensive margin at global level, see Table S9 in the Supplementary Material.
} 

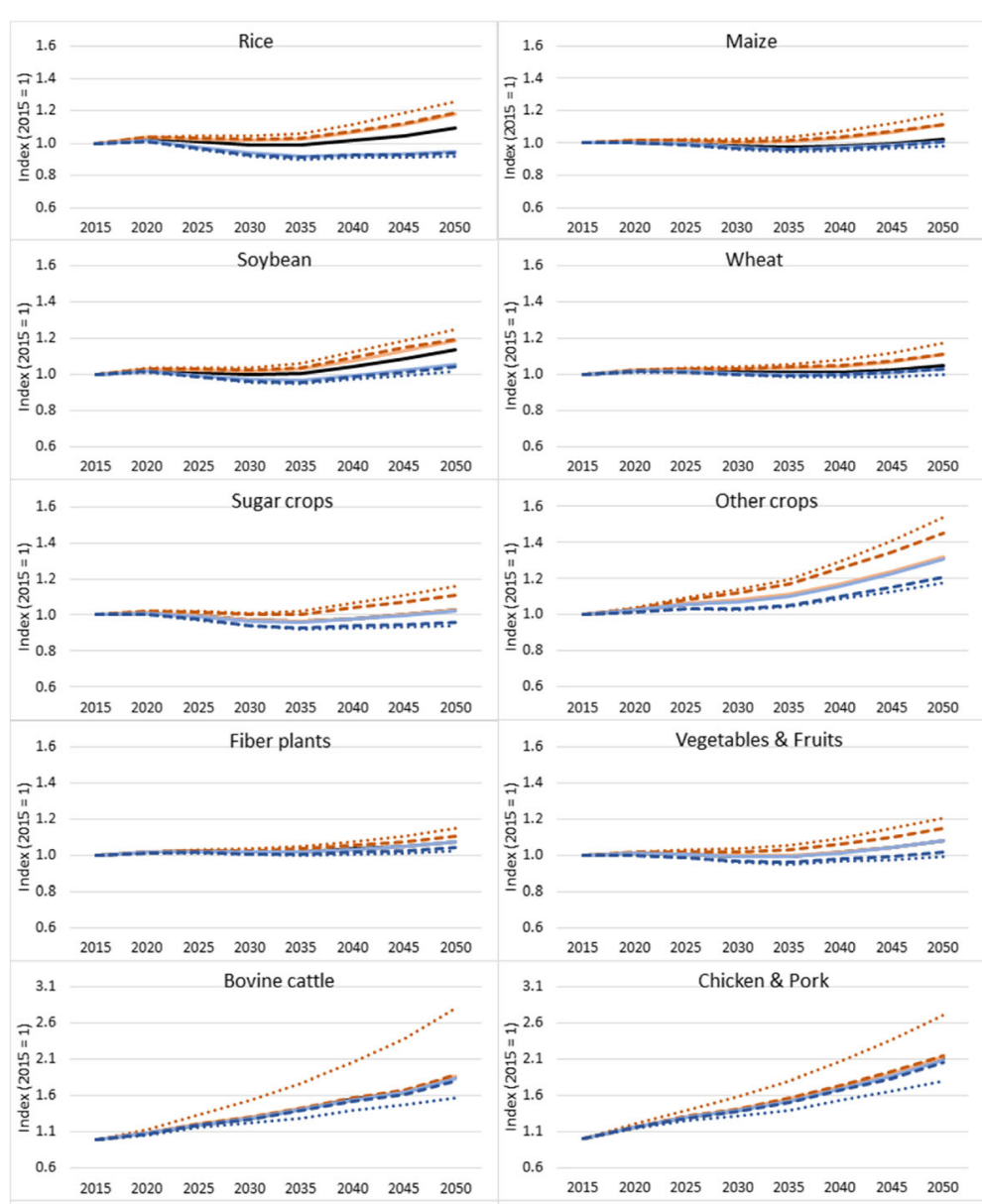

$\begin{array}{llllllll}2015 & 2020 & 2025 & 2030 & 2035 & 2040 & 2045 & 2050\end{array}$
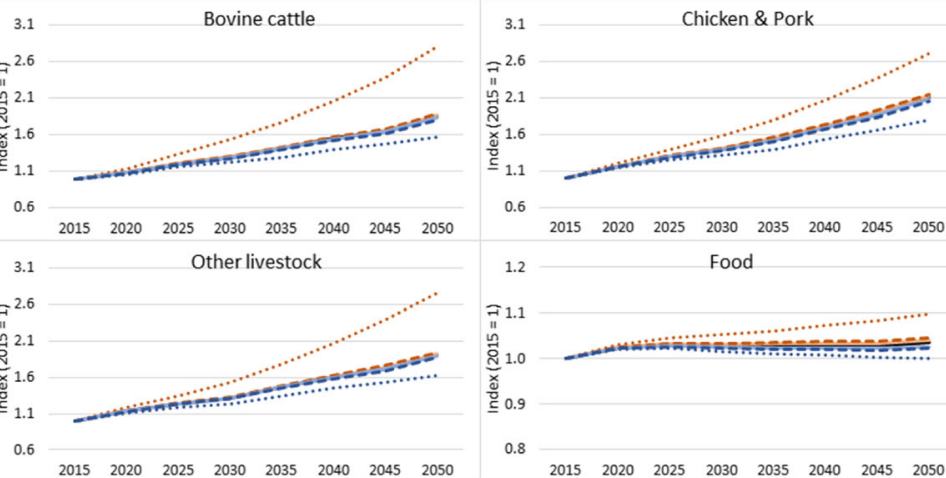

1.2

Food
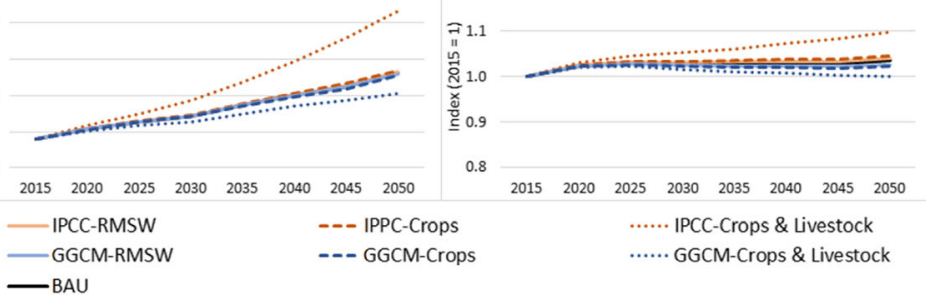

Fig. 5 Global price indexes for crops, livestock, and food sectors

expense of pasture land, and secondarily, managed forest. In the IPCC Crops \& Livestock scenario, there is a large increase in pasture and a small increase in cropland, at the expense of managed forest. Under the GGCM scenarios, these changes are reversed. In the Crops \& Livestock scenario, both pastureland and cropland decrease and land in managed forests increase. The relatively minor changes in natural forest and natural grass areas reflects calibration of the land transformation functions to observed land supply elasticities. Larger 


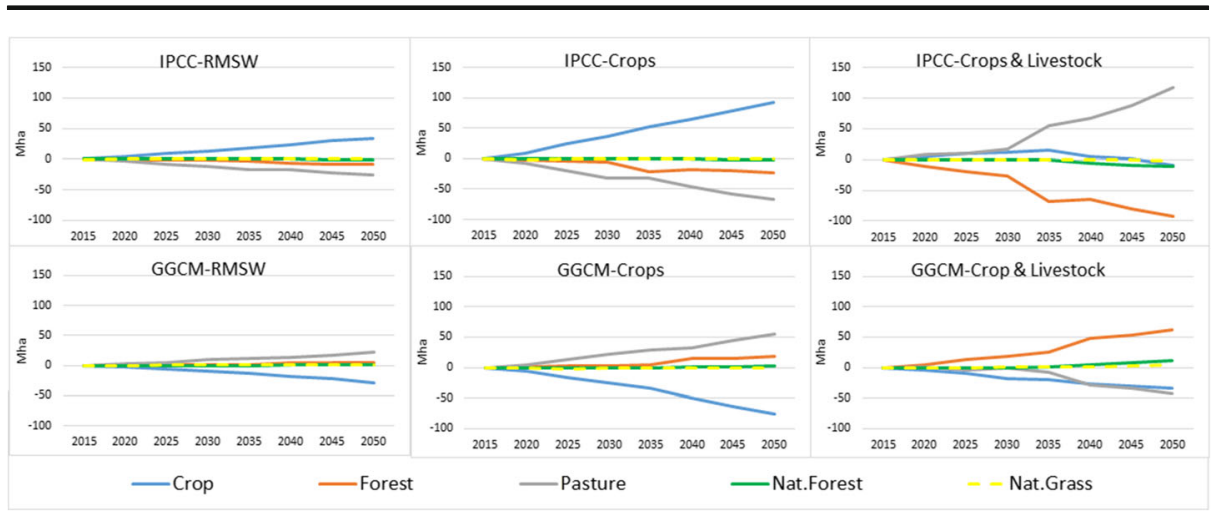

Fig. 6 Land use changes in the impact scenarios relative to BAU, from 2015 to 2050 (Mha)

economic and population growth, combined with high income elasticities in Africa, drive a spike in global forest conversion in 2035 under negative climate impacts.

Some lessons can be drawn from Fig. 6. First, future land use trajectories depend, as expected, on the overall sign of yield impact. Second, failure to include productivity impacts across all commodities can give a misleading picture of land use change. And third, our results suggest that further land use change due to climate change, at least given the magnitude of impact seen in these median scenarios, is mainly driven by a reallocation of existing managed land areas, with small additional impact on natural areas.

The regional land use changes play out fairly similarly to the results at the global level. IPCC and GGCM RMSW and Crops scenarios on land use are close to the mirror image of one another due to the opposite directions of the climate impacts on yields. Under the IPCC Crops $\&$ Livestock scenario, negative climate impacts on pastures and livestock force the most of land use changes as an adaptation mechanism, since pasture areas expand in all regions and cropland increases in some regions. Under the GGCM Crops \& Livestock scenario, there is a relief of pressure on agricultural areas in all regions (see Table S8 and Fig. S9 and their discussion in the Supplementary Material). ${ }^{9}$

\section{Conclusions}

We noted at the outset some glaring oversights in the literature in understanding the full impacts of climate change on agriculture. While there has been considerable research aimed at estimating climate impacts on crops over the last 30 years, much of the focus has been on a few major crops (rice, maize, soybean, and wheat). Moreover, livestock production is an important component of agriculture, but studies about climate impacts on livestock have not been combined with specific climate scenarios and scaled up to provide regional estimates for the entire world. Agricultural markets are international, and shocks in one region of the world, or one set of commodities, reverberate through these markets. Only focusing on a few crops can be highly misleading. Understanding the overall risks to food supply, consumer wellbeing, agricultural markets, and the environmental implications of climate change through its

\footnotetext{
${ }^{9}$ See the Supplementary Material (Figure S10) for results and discussion about $\mathrm{CO}_{2}$ land use change emissions.
} 
effect on agriculture requires the consideration of all these interconnected commodities and all regions of the world.

Another glaring limitation of many of the crop modeling exercises is that the complexity of the models and the required data make large-scale simulation of these models expensive. The result has been that these site-based models are typically run at relatively few sites over a region. As a result, it is unclear whether the few sites are truly representative of the entire region. The southern border of northern temperate cropping areas may be very severely negatively affected, while the crop productivity may increase on the northern border of the cropping region and expand further north, no longer limited as much by cold weather. Capturing the gradient of these impacts across an entire region would require a relatively dense network of crop modeling sites. Stepping into this gap are a relatively new set of global gridded crop models that estimate crop yields in every land grid, often at a $0.5 \times 0.5$ latitudelongitude resolution. The results across available models that have been developed for rice, maize, soybean, and wheat show considerable variability. However, a median estimate for this class of models impacts on crop productivity on currently cropped land is generally positive in all regions of the world, when aggregated to a set of world regions. This is almost the complete reverse of median results, largely from site-based models reviewed by the IPCC. Except for a few crops in a few regions, those estimates suggest a negative impact on crop productivity in almost all regions.

While it was beyond the scope of this research to try to fill in productivity shocks for all crops and livestock for the entire world, we made a simple assumption to test how only focusing on the few crops for which we had estimates might be leading to a biased picture of the risks of climate change to agriculture. Our simple assumption was to extend the regional average impacts on rice, maize, soybean, and wheat, first to all crops, and then to all crops and all livestock commodities. This is meant only to be a sensitivity analysis. With a diversity of crops and livestock types, we might expect some differential productivity shocks. And, if we were very fortunate, and negative effects on some commodities were canceled by positive effects on others, then they might completely balance out. However, that seems unlikely. We evaluated these sensitivities using broad socioeconomic metrics (economy-wide welfare change, effect on the representative agent's food budget), agriculture sector metrics (commodity output and prices), and environmental metrics (land use changes). We find that omitting impacts on a large set of commodities could potentially lead to a severe underestimation of climate impacts on economies and household food budgets. Some key findings of this analysis:

1. Global aggregate welfare impacts were six to 13 times larger when we included direct climate impacts on all crops and all livestock compared with scenarios where just rice, maize, soybean, and wheat were affected. We trace the reason for the more-thanproportional increase in the welfare impact to the fact that expansion of land area devoted to a commodity's production is a major source of adaptation. When all commodities are directly affected, that avenue of adaptation is limited. Heterogeneous climate impacts on crops would promote relevant shifts among crops, but we lack extensive estimates about such heterogeneity in the literature.

2. Food budget impacts are on the order of $3 \%$ or less when only crops are directly affected by climate change, but the impact is 10 to $25 \%$ in many developing country regions when all crops and all livestock commodities are directly affected by climate change. The disproportionate jump in the budget effect can be traced to several factors. More limited 
ability to adapt through land expansion, less ability to substitute among food commodities, and the fact that there is less value added in livestock products, as a proportion of final consumer cost, and so more of the commodity price increase shows up in the consumer budget, and even more so for those regions with lower incomes. This jump could change the outcome from a minor annoyance to a major threat to food security.

3. Commodity output impacts at the global level were generally less than the direct impacts on yields, and as food is generally price inelastic, lead to rising prices that create incentives to production growth. Regional impacts on output were more dependent on the yield change in the region relative to the average effect across the world, with production shifting toward those with a less negative or more positive impact, and away from those regions more severely, or less positively affected. Including all crops and livestock amplified the effects on commodity prices, especially in livestock products affected indirectly through the price of feed and directly by its effect on livestock productivity.

4. Land use change (and $\mathrm{CO}_{2}$ emissions) showed some of the most complex and surprising effects, with the direction of impact changing as we included direct impacts on all crops and livestock compared with simulations where we included direct effects only on crops. When only crops were directly affected, we found that, generally, negative yield effects lead to lower net land use carbon emissions because crops expanded onto pasture, and with more intense management carbon stocks on the new cropland increased. But when these shocks were expanded to all crops and livestock, pasture increased, leading to an increase in net carbon emissions to the atmosphere.

5. Taking the median of set runs of emulated GGCMs, we found positive yield effects across rice, maize, soybean, and wheat, and these provided generally improved overall welfare gains, lower household food budgets, increased commodity output, lower commodity prices, but possibly increased $\mathrm{CO}_{2}$ emissions from land use. Similar to results from sitebased models reviewed in the IPCC, there were a wide range of impacts from GGCMs, so caution is warranted in comparing those median effects.

While this analysis must be considered largely as a sensitivity analysis, and by construction may have exaggerated some of the conclusions - perhaps rice, maize, soybean, and wheat yields impacts could all be negative in a region with other crops mostly positive, offsetting rather than amplifying impacts - the conclusions we reach indicate that (i) the agricultural research community needs to place a high priority on expanding efforts to estimate climate impacts on many more crops, and to include impacts on livestock; (ii) careful comparison of the GGCMs and traditional site-based models are needed. Given that various of the GGCMs have been designed with different purposes in mind, further investigation of these differences, especially as it affects estimates of yield response, would be useful for the broader policy community. The site-based models have been used much longer than the GGCMs and are generally better calibrated - and the IPCC has tended to rely more heavily on this set of models. The GGCMs have an advantage in fine spatial detail. Until the differences among these approaches are resolved, it seems necessary to interpret the broad range as representative of large structural uncertainties in crop model representation of responses to climate change, a cautionary note for use of results in policy discussions.

Finally, we offer some observations on how economic models, such as the CGE model we applied, can be improved. First, climate impacts can be represented as an impact on a specific 
input (land, or a calf as it enters a feedlot, for example), as a decrease in output, or as higher costs of inputs. More attention to the way impacts are represented is needed, which is supported by a recent paper emphasizing that the impact on farm labor productivity may be much more important than the direct impact on crop yields (Hertel and Lima 2020). Second, more joint efforts with the animal science community are needed to better capture the variety of adaptation strategies possible in the livestock sectors in economic models. Third, the representation of the food industry needs to be examined in more detail. Most agricultural products are intermediate inputs to a food sector, where they are usually treated as perfectly complementary (Leontief) inputs, which likely underrepresents possible adaptation within the food sector. A compensating result may be more relocation of crops and livestock among regions, and greater land substitution, but further investigation regarding substitution possibilities at the food industry level would help test the importance of the production structure of the sector.

Supplementary Information The online version contains supplementary material available at https://oi.org/ 10.1007/s10584-021-03119-8.

Authors' contributions All authors contributed to the study conception and design. Data collection, model simulation, and analysis were performed by Gurgel and Blanc. First draft was written by Reilly and all authors commented on previous versions. All authors read and approved the final manuscript.

Funding Reilly and Blanc were supported under funding from the Department of Energy, Office of Science under DE-FG02-94ER61937. Gurgel was supported by the Brazilian Council for Scientific and Technological Development - CNPQ (processes 312975/2017-1 and 449951/2014-6). The authors also gratefully acknowledge financial support for Integrated Global Systems Model (IGSM) development by other government, industry, and foundation sponsors of the MIT Joint Program on the Science and Policy of Global Change. For a complete list of sponsors and US government funding sources, please visit http://globalchange.mit.edu/sponsors/all.

Availability of data and material Data and material are available under request. Data from the Global Trade Analysis Project (GTAP) used to build the socioeconomic model is not free distributed (see: https://www.gtap. agecon.purdue.edu/databases/v8/default.asp).

Code availability A public version of the EPPA6 model is available at the page https://globalchange.mit.edu/ research/research-tools/human-system-model/download

\section{Declarations}

Conflicts of interest/competing interests The authors declare that they have no conflict of interest.

Open Access This article is licensed under a Creative Commons Attribution 4.0 International License, which permits use, sharing, adaptation, distribution and reproduction in any medium or format, as long as you give appropriate credit to the original author(s) and the source, provide a link to the Creative Commons licence, and indicate if changes were made. The images or other third party material in this article are included in the article's Creative Commons licence, unless indicated otherwise in a credit line to the material. If material is not included in the article's Creative Commons licence and your intended use is not permitted by statutory regulation or exceeds the permitted use, you will need to obtain permission directly from the copyright holder. To view a copy of this licence, visit http://creativecommons.org/licenses/by/4.0/. 


\section{References}

Antle JM, Stöckle CO (2017) Climate impacts on agriculture: insights from agronomic-economic analysis. Rev Environ Econ Policy 11(2):299-318

Baldos ULC, Hertel TW (2012) Development of a GTAP 8 land use and land cover data base for years 2004 and 2007. GTAP Research Memorandum 23, September (https://www.gtap.agecon.purdue.edu/resources/ download/6048.pdf)

Bassu S, Brisson N, Durand JL, Boote K et al (2014) How do various maize crop models vary in their responses to climate change factors? Glob Chang Biol 20(7):2301-2320

Blanc E (2017a) Statistical emulators of maize, rice, soybean and wheat yields from global gridded crop models. Agric For Meteorol 236(617):145-161

Blanc E (2017b) Aggregation of gridded emulated rainfed crop yield projections at the national or regional level. Journal of Global Economic Analysis 2(2):112-127

Blanc E, Reilly J (2017) Approaches to assessing climate change impacts on agriculture: an overview of the debate. Environ Econ Policy 11(2):247-257

Blanc E, Schlenker W (2017) The use of panel models in assessments of climate impacts on agriculture. Rev Environ Econ Policy 11(2):258-279

Boden TA, Marland G, Andres RJ (2010) Global, regional, and national fossil-fuel CO2 emissions. Carbon Dioxide Information Analysis Center, Oak Ridge National Laboratory, U.S. Department of Energy, Oak Ridge, Tenn., USA

Bond TC, Bhardwaj E, Dong R, Jogani R et al (2007) Historical emissions of black and organic carbon aerosol from energy-related combustion, 1850-2000. Glob Biogeochem Cycles 21(2):1-16

Chen Y-HH, Paltsev S, Reilly J, Morris JF, Babiker MH (2015) The MIT EPPA6 model: economic growth, energy use, and food consumption. MIT JPSPGC Report 278, March, 43 p. (https://globalchange.mit.edu/ sites/default/files/MITJPSPGC_Rpt278.pdf)

Chen Y-HH, Paltsev S, Reilly J, Morris J, et al. (2017) The MIT Economic Projection and Policy Analysis (EPPA) model: version 5. MIT-JPSPGC Technical Note 16, March (https://globalchange.mit.edu/sites/ default/files/MITJPSPGC_TechNote16.pdf)

European Commission (2011) Emission Database for Global Atmospheric Research (EDGAR), release version 4.2, Joint Research Centre (JRC)/Netherlands Environmental Assessment Agency (PBL), EC. (http://edgar. jrc.ec.europa.eu)

FAO (2019) Food and Agriculture Data (http://www.fao.org/faostat/en/\#data)

Felzer B, Kicklighter D, Melillo J, Wang C (2004) Effects of ozone on net primary production and carbon sequestration in the conterminous United States using a biogeochemistry model. Tellus B 56(3):230-248

Gornall J, Betts R, Burke E, Clark R, Camp J, Willett K, Wiltshire A (2010) Implications of climate change for agricultural productivity in the early twenty-first century. Philos Trans R Soc B: Biological Sciences 365(1554):2973-2989

Gurgel A, Chen Y-HH, Paltsev S, Reilly J (2016) CGE models: linking natural resources to the CGE framework. In: World scientific reference on natural resources and environmental policy in the era of global change, Vol. 3. Computable general equilibrium models, A. Dinar et al. (eds.), World Scientific Publishing: Hackensack, U.S., Chapter 3, pp. 57-98

Hertel TW (1997) Global trade analysis: modeling and applications. Cambridge University Press, Cambridge, p 379

Hertel TW, de Lima CZ (2020) Viewpoint: Climate impacts on agriculture: Searching for keys under the streetlight. Food Policy 95:101954

Hurtt GC, Frolking S, Fearon MG (2006) The underpinnings of land-use history: three centuries of global gridded land-use transitions, wood-harvest activity, and resulting secondary lands. Glob Chang Biol 12(7): 1208-1229

International Energy Agency (2012) World energy outlook. International Energy Agency, Paris (http://www. worldenergyoutlook.org/publications/weo-2012/)

Mendelsohn RO, Massetti E (2017) The use of cross-sectional analysis to measure climate impacts on agriculture: theory and evidence. Rev Environ Econ Policy 11(2):280-298

Müller C, Elliott J, Chryssanthacopoulos J, Arneth A et al (2017) Global gridded crop model evaluation: benchmarking, skills, deficiencies and implications. Geosci Model Dev 10(4):1403-1422

Narayanan BG, Aguiar A, McDougall R (eds.) (2012) Global trade, assistance, and production: the GTAP 8 Data Base. Center for Global Trade Analysis, Purdue University (https://www.gtap.agecon.purdue.edu/databases/ v8/v8_doco.asp)

Nelson GC, van der Mensbrugghe D, Ahammad H, Blanc E et al (2014) Agriculture and climate change in global scenarios: why don't the models agree? Agric Econ 45(1):85-101 
Porter JR, Xie L, Challinor AJ, Cochrane K, Howden SM, Iqbal MM, Lobell DB, Travasso MI et al. (2014) Food security and food production systems. In: Climate change 2014: impacts, adaptation, and vulnerability. Part A: global and sectoral aspects. Contribution of Working Group II to the Fifth Assessment Report of the Intergovernmental Panel on Climate Change [Field CB, et al. (eds.)] Cambridge University Press, Cambridge, United Kingdom and New York, NY, USA, pp. 485-533

Ramankutty N (2012) Global Cropland and Pasture Data: 1700-2007. LUGE (Land Use and the Global Environment) laboratory, Department of Geography, McGill University, Montreal, Quebec, Canada

Ray DK, Mueller ND, West PC, Foley JA (2013) Yield trends are insufficient to double global crop production by 2050. PLoS One 8(6):e66428

Rojas-Downing MM, Nejadhashemi AP, Harrigan T, Woznicki SA (2017) Climate change and livestock: impacts, adaptation, and mitigation. Clim Risk Manag 16:145-163

Rosenzweig C, Elliott J, Deryng D, Ruane AC et al (2014) Assessing agricultural risks of climate change in the 21 st century in a global gridded crop model intercomparison. Proc Natl Acad Sci 111(9):3268-3273

Rutherford TF (1995) Extension of GAMS for complementarity problems arising in applied economic analysis. J Econ Dyn Control 19(8):1299-1324

Rutherford TF (1999) Applied general equilibrium modeling with MPSGE as a GAMS subsystem: an overview of the modeling framework and syntax. Comput Econ 14:1-46

Schlosser CA, Gao X, Strzepek K, Sokolov A (2013) Quantifying the likelihood of regional climate change: a hybridized approach. J Clim 26:3394-3414

Schmitz C, van Meijl H, Kyle P, Nelson GC et al (2014) Land-use change trajectories up to 2050: insights from a global agro-economic model comparison. Agric Econ 45(1):69-84

Summer A, Lora I, Formaggioni P, Gottardo F (2019) Impact of heat stress on milk and meat production. Anim Front 9(1):39-46

Publisher's note Springer Nature remains neutral with regard to jurisdictional claims in published maps and institutional affiliations. 